\title{
Blast Wind: Phantomenology, Modernity, and the Remains of Art
}

\author{
Gray Kochhar-Lindgren
}

Ghosts are appearing in our public squares at noon and at midnight they become visible as shimmering forms that buzz along the edges of the neon glare. They haunt our screens and emerge from the radiant cores of our most sophisticated technologies, the outgrowth of the violence of our domination of the earth-body. Ghosts accompany the installation of the apparatus of rationality installed by techno-capitalism that has finally split the shadow from its object, leaving the shadow burned into the stone as the object, vanishing, is vaporized in heat and light. Ghosts, as Avery Gordon has reminded us, are a "generalizable social phenomenon" that mark the presence of a traumatic history, and with the logic of a strange and torsional doubling, they wander as free-floating symptoms along the (in)visible seams of the wounds of contemporaneity. But they also mark out the spaces-between from which the unexpected can emerge that can grant us the to-come of a futurity.

The ghost in the early 21 st century marks the return of the phantasmata-image, shadow, affect, body — that the central philosophical tradition of the idealism that runs from Plato through Husserl and beyond has worked so assiduously to cast aside and to exclude from the discourse of truth. This is the return of the repressed and the structure of such a return entails the fracturing of the metaphysical compact between the quantifiable and the true, the true and the logical, and the true as a form beyond appearance. This is not to dismiss the quantifiable, the logical, and necessity of ideal forms; it is, however, to reconfigure these and other terms in the different light of the chiaroscuro of phantomenology. Thus, we have the necessary appearance and development of visual cultures, affect studies, and gender and body studies. The shadow of the ghost cast aside by philosophy must receive its due.

In W.G. Sebald's Vertigo, the narrator comments that:

I was unable even to determine whether I was in the land of the living or already in another place. Nor did this lapse in memory improve in the slightest after I climbed to the topmost gallery of the cathedral and from there, best by recurring fits of vertigo, gazed out upon the dusky, hazy panorama of a city now altogether alien to me.... (115-116)

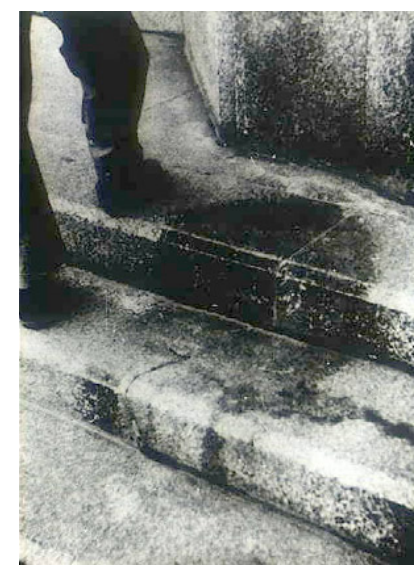


This is the site of the phantoms, the site of everyday life after the catastrophes of the 20th century and within the catastrophe, as well as within the promise, of history itself. Since for a long time now we have not had any compass bearings to orient ourselves, we are not quite sure where we are, although we know that both the living and the dead cross our field of vision. Perplexed by our dizziness at what we see, we change our angle of view, trying to climb higher in the ruined cathedral in order to see things more as an ordered whole, but even then our city is alien to us, beset by dust and dusk. A shadow spreads that obscures the city of human habitation, and then a stiff wind arises as if from nowhere into which all of us are leaning as we struggle to maintain our balance. This is the blast wind of modernity. It is relentless.

This blast wind roars at us from every side, along many ridges and through many valleys and subterranean tunnels, and one of the central sites at which this wind becomes visible is Hiroshima, a city devastated by a blast, a city where shadows remain burned into steps and onto walls even while their original objects are obliterated, vanished except for a smudged trace. The technologies that precede the splitting and chaining of the atom, photography and the cinema for example, mark the installation of the power to split the natural order of things-to sever the shadow from its object — and to ghost the past in the ghosted present.

Now, however, faced with the nuclear technologies of both the atom and the gene, we find ourselves in an intensified vertigo that radicalizes that of the lost compass orientation. The Federation of American Scientists explains the blast in this way:

When the expanding blast wave from a nuclear air burst strikes the surface of the earth it is reflected, and the reflected wave reinforces and intensifies the primary wave. Targets in the vicinity of ground zero may actually be subjected to two blast waves: the initial or incident wave, followed slightly later by a secondary reflected wave. This limited region close to ground zero in which the incident and reflected waves are separate is known as the region of regular reflection. Beyond the area of regular reflection as it travels through air which is already heated and compressed by the incident blast wave, the reflected wave will move much more rapidly and will very quickly catch up with the incident wave. The two then fuse to form a combined wave front known as the Mach stem. The height of the Mach stem increases as the blast wave moves outward and becomes a nearly vertical blast front. (http://www.fas.org/nuke/intro/nuke/blast.htm)

We stand directly in the path of that vertical blast front, a destructive wall of fire created by the interpenetration of a primary incident wave and the secondary reflected wave. The original and the secondary become inseparable and a new hybrid entity that increases in height as it moves toward and through us is created. This is the moment of the emergence of a spectrality different than has always accompanied the questions of appearance, meaning, the human, and of death, although these, too, are still active. As Akira Lippit insists, the "atomic radiation that ended the war in Japan unleashed an excess visuality that threatened the material and conceptual dimension of human interiority and exteriority. It assailed the bodies it touched, seared and penetrated them, annihilating the limits that established human existence in the world" (4).

This is the moment of phantomenology and the remains of art. The philosophical history of reason, the empirical world of culture, and the enigmatic presence of art find themselves isomorphically reflecting one another as modernity morphs into another phase. As T.W. Adorno has commented, "[O]nly polemically does reason present itself to the knower as total reality, while only in traces and ruins is it prepared to hope that it will ever come across correct and just reality" (AP 121). These traces, this disorderly pile of ruins strewn across the earthscape, are constitutive of the work of reason, the work of culture, and the work of art. The logic of the phantom is one phrase for the site, which is nowhere and anywhere but which precipitates at places like Hiroshima where the material forms of thought crisscross one another, looping back on one another in a spooky and snarled entanglement.

In an interview published in its original version in Le Monde de l'éducation, Jacques Derrida once again recapitulates his notion of the trace and of the remainder, which, as with all words, is neither here nor there and both here and there. "A trace," he says to his interviewer, "is never present, fully present, by definition; it inscribes in itself the reference to the specter of something else" (PM 151). There is sameness and difference; there is an enigmatic "itself"; and there is a writing that, as itself, refers to the specter of something else: and only the specter of that something else, never something-in-itself, is available. This is an expression that articulates the most banal of all possible experiences; it defines, or regulates or bounds, any ordinary experience at all. The simplest moment is infinitely strange.

Derrida continues, reminding us through the talking-listening that has become reading-writing and that arrives from the other side of life, that "[T] he remaining of the remainder is not reducible to an actual residue, or to what is left after a subtraction either. The remainder is not, it is not a being, not a modification of that which is. Like 
the trace, the remaining offers itself for thought before or beyond being..." (PM 151). There is an offering before or beyond the "is" that serves as a copulating function of identity. Being is not first and there can never be a first philosophy. The remainder is not second, a modification or the result of a subtraction from that-which-is, for thatwhich-is depends on the structure of a trace in order to appear as a present. This is first philosophy as the appearance of the uncanny. This is deconstruction and it is profoundly confusing, since it both undergirds and undermines the structure of logical and empirical clarity, of intellectual or sensible intuitions of essences.

We can, and should, become clearer about ideas and beings-we should do the best science and logical analysis possible-but this clarity emerges from an obscurity, an inscrutability that can never itself be brought to the point of distinctiveness, but which nonetheless offers a remainder, a trace of itself. As we have seen, we do not live in absolute light or absolute darkness; instead, the world is chiaroscuro: shadowed, ghostly, and, therefore, able to be full-bodied in its frothing forth of singularities.

Derrida, like others, associates the remainder with ashes, "remains without a substantial remainder, essentially, but which have to be taken account of and without which there would neither be accounting nor calculation, nor a principle of reason able to give an account or a rationale, nor a being as such" (PM 152). What an absurd claim: the rational in its many forms of power, including the possibility of accountability itself, is founded upon the slowly drifting lightness of ashes, always pluralized and always only one.

And it is absurd not only because the rational cannot account for it — the concept of truth cannot be fulfilledbut also because one insignificant particular, ashes, comes to stand for the entirety of Being and the possibility of both understanding and memory. This is the holocaust, the catastrophe, and the hope. There is no Being assuch — and this is perhaps the most succinct statement of Derrida's critique of Husserl-but there is being as-if. Directionless, it drifts in play with the slightest whisper of a breeze. And so, while there is no remainder as such, there are "remainder effects, in the sense of a result or a present, idealizable, ideally iterable residue...sentences fixed on paper, more or less readable and reproducible..." (PM 152). This is the phantomenological essence of philosophy.

There is also a phantomenological essence of cultural production that is schematized by Slavoj Žižek in "The Specter of Ideology." In this brief text, Žižek examines ideology as the "generative matrix that regulates the relationship between visible and nonvisible, between imaginable and nonimaginable, as well as the changes in this relationship" (1) that, in turn, is based on the Lacanian analysis of the relationship between the real, the symbolic, and the structure of fiction. "[1]deology has nothing to do with 'illusion," "Žižek explains, "with a mistaken, distorted representation of its social context.... a political standpoint can be quite accurate ('true') as to its objective content, yet thoroughly ideological..."(7). Just as we have seen with the philosophical critique of idealism, so, too, in this understanding of the ideological we are always in a symbolized world rather than in a realist world "as such." There is no "original" world to which an adaptation occurs called "the fictional" or the "ideological," but the world as such is always the world as-if. There is the play of faculties, the conflict of interpretations, and the possibility of possibility.

There is always an historical specificity to the ideological-Žižek is particularly interested in this text in the "empty pleasures" of late capitalism-but this is fundamentally related to the structure of sociality as symbolically constructed. Žižek emphasizes that this is not the same as to be entrapped in the representationalist dilemma of the "only" discursive universe that some forms of postmodernism have promoted.

It all hinges on our persisting in this impossible position: although no clear line of demarcation separates ideology from reality, although ideology is already at work in everything we experience as 'reality', we must nonetheless maintain the tension that keeps the critique of ideology alive. ...it is possible to assume a place that enables us to maintain a distance from it, but this place from which one can denounce ideology must remain empty, it cannot be occupied by any positively determined reality.... (17)

This "empty space" carries the names of possibility, ghost, specter, writing, and art, and though it cannot be definitively inhabited by a positive determination, it must always be inhabiting itself with new determinations that then freely give way to others.

This emptiness is structured like a fountain, a structure always rejuvenated and overflowing its boundaries. (Rilke is the one who knew this most completely.) It is the mysterious space of emergence into the symbolic dimension of human activity. Žižek, following Lacan, attempts to distinguish the symbolic from the real, which is a difficult articulation to draw. The real, which is not symbolizable, can only be marked with an X. The non-symbolizable real returns as "spectral apparitions" and, therefore:

'specter' is not to be confused with 'symbolic fiction,' with the fact that reality itself has the structure of a fiction in that 
it is symbolically constructed; the notions of specter and (symbolic) fiction are co-dependent in their very incompatibility (they are 'complementary' in the quantum-mechanical sense). To put it simply, reality is never directly 'itself', it presents itself only via its incomplete-failed symbolization, and spectral apparitions emerge in this very gap that forever separates reality from the real, and on account of which reality has the character of a (symbolic) fiction: the specter gives body to that which escapes (the symbolically structured) reality. (21)

But in "giving body to," the specter must show itself as an apparition, an appearance, a phantom trace that participates in the logic of the is-not, part of which divides itself toward the symbolized. When the symbolic is considered closed we find ourselves in the state of ideology; when it is considered as open, a necessary condition for its operation, then we find ourselves in the impossible position of witnessing the appearance of the spectral. Critique, which is creative, simply means having the tools to pry open the ideological and to position the magic goggles to see the difference between the two formations.

"The preideological 'kernel' of ideology," Žižek continues, "consists of the spectral apparition that fills up the hole of the real...What the specter conceals is not reality but its 'primordially repressed', the irrepresentable X on whose 'repression' reality itself is founded" (21).2 The "pre-," which should no longer surprise us, indicates a before or beyond of the isness of the world as it appears as empirically stable and fully present to the thinking senses. The real is a tear that, nothing in itself but a jagged edge, shows us a hole, a shadow on the face of things. Art, philosophy, and psychoanalysis feel their way slowly, with painstaking care, along the edges of this edge that drops away into nothingness. All of these reveal not a stabilized commodity fetishism that is an illusory modification of the real, but, instead an "uncanny chimera at work in the very heart of the actual process of social production" (30, Note 8). The social, in all of its forms, is spectral. As Marx put it so memorably:

we have the complete mystification of the capitalist mode of production, the reification of social relations and immediate coalescence of the material production relations with their historical and social determination. It is an enchanted, perverted, topsy-turvy world, in which Monsieur le Capital and Madame la Terre do their ghost-walking as social characters and at the same time directly as things. (Capital III, ch. 48)

Everything is always doubled, including the doubled. And as the network of relations shifts and slides, looking for a while like a thing and then like a thing that vanishes_-something like a toxic mortgage_-meanings, too, slide about. This is the process of cultural signification, the face of the spectral that appears in our direction, and this includes the production of the arts.

In The Emigrants, for example, Sebald's authorial description of Sebald's narration of the text within the text, notes that the process is as arduous as Max Ferber's violent and unforgiving technique of painting-the arts always cross over one another - and that there is a fundamental, inescapable anxiety about the "entire questionable business of writing. I had covered hundreds of pages with my scribble, in pencil and ballpoint. By far the great part had been crossed out, discarded, and obliterated by additions. Even what I ultimately salvaged as a 'final' version seemed to me a thing of shreds and patches, utterly botched" (230). All additions obliterate the past, but the past continues to appear as trace, as smudge, and all of cultural production is merely a series of "shreds and patches," a torn fabric of remains through which we sometimes see, or think we see, the blue sky of the hole of the real. The arts stage this scenario.

When in Paper Machine Antoine Spire (the questioner) turns to film, he reminds Derrida that the "cinema could be said to be an elsewhere edged with mirrors, but where it's no longer a question of constructing yourself, a body, but rather of haunting the screen." This beautifully provocative definition of the cinema echoes how mirrors and shadows play off of one another in the history of philosophy, painting, in new media, and in films such as Schatten. The screen functions narcissistically to construct the body of identifications, but since those supposedly mirroring identifications are projected from an elsewhere, the mirror is always shadowed by the otherness of that elsewhere, which therefore deconstructs the body of identifications. Responding to Spire, Derrida comments that "spectrality is at work everywhere, and more than ever, in an original way, in the reproducible virtuality of photography or cinema" (158).

This comparative logic of the "more than ever" is the difficult doubling of the logic of the phantom that we are attempting to track, for, although spectrality has always been operative, it now takes an original form, late in the day, as the technologies of reproduction come on line in ever more penetrating and powerful ways.

The bombings that ended Japan's imperialist activities had introduced...a form of warfare that circulated through a dense matrix of visuality, displacing any access to a stable referent. At Hiroshima, and then Nagasaki, a blinding flash vaporized 
entire bodies, leaving behind only shadow traces. The initial destruction was followed by waves of invisible radiation, which infiltrated the survivors' bodies imperceptibly. (Lippit 86)

We are all suffering from this blow, from this radioactive effect of the blast wind that, though detectable, is not directly visible; that governs, but in unpredictable ways, the registers of the visible and the invisible, the possible and the impossible. It is a dense concatenation of thresholds where ghosts cross between worlds.

The wind leaves traces behind: shadows, ruins, and a little bit of waste from which to make things. Writing of the Japanese Neo-Dada artists in the 1960s, Tōno Yoshiaki notes that their exhibits

reflected the immense junkyard of the teeming city of Tokyo. The junk which they first saw, which influenced their way of feeling objects, was the junk of the burned ruins of the city during the war. The blasted city had been their playground; their first toys had been bottles melted into distortion from fire bombs, pieces of roof beams found in the ashes. Now their shows were full of these junk flowers, with their queer blossoms. (cited in Munroe:157)

And all this junk has been shaped into new forms by the hands of artists, has been created to serve as the meeting point of the past and the future. Art, distorted and transformed debris from the nuclear strike, embodies the sedimented history of the past, witnesses the mangling of the world.

This strange blossoming of a glass flower - the artifactuality of art- opens up possibilities for the future. The artistic, with the semblance of its seeming, creates a discourse of critical aesthetics, of philosophy, that responds to the question of the truth of the object. The art-object also, however, creates a space in the mode of silence as a transmitting placeholder for the creation of the next object. The present object opens in all directions-the past, the present, the future, the surface, and the depths — as it generates itself and others out of its own supplemental traces that it strews about, like fragrant petals, in the noise of the world.

Art, then, can only be a site of ruins, a place that testifies to the blast wind of obliteration, but, in that very testimony art gives a place for the ghosts to gather and disperse, to come and speak with each other and with us before turning. Art, which installs itself in the very heart of the ancient dream of philosophy, insures that each phenomenon is always a phantasm and thus we can be assured that the apparitions will speak in the grotto of miracles. We cannot understand this speech, not very well, but it keeps us listening. The remains of art, in other words, remain; they grant us a reminder.

\section{References}

Adorno, Theodore. 1977. "The Actuality of Philosophy." Telos 31 (Spring):120-133.

Derrida, Jacques. 2004. Eyes of the University: Right to Philosophy 2. Translated by Jan Plug and Others. Stanford, CA: Stanford University Press.

-----. 2005. Paper Machine. Translated by Rachel Bowlby. Stanford: Stanford University Press.

Federation of American Scientists. January 6, 2010 (http://www. fas.org/nuke/intro/nuke/blast.htm).

Gordon, Avery. 1996. Ghostly Matters: Haunting and the Sociological Imagination. Minneapolis: University of Minnesota Press.

Lippit, Akira Mizuta. 2005. Atomic Light (Shadow Optics). Minneapolis: University of Minnesota Press.

Marx, Karl. 1981. Capital: A Critique of Political Economy, edited by Frederick Engels. New York: International.
Munroe, Alexandra, ed. 1994. Japanese Art After 1945: Scream Against the Sky. New York: Harry N. Abrams.

Sebald, W.G. 1997. Emigrants. Translated by Michael Hulse. New York: New Directions.

-----. 1999. Vertigo. Translated by Michael Hulse. New York: New Directions.

"Shadow on the Step of the Sumitomo Bank." January 6, 2010 (https://eee.uci.edu/clients/bjbecker/SpinningWeb/riddley3. html).

Žižek, Slavoj. 1994. “The Spectre of Ideology.” Mapping Ideology, edited by Slavoj Žižek. London: Verso. 
